\section{Postdoctoral research positions as preparation for an academic career}

\author{
GERLESE S. ÅKERLIND
}

The Australian National University

Centre for Educational Development and Academic Methods,

The Australian National University, 0200

Australia

E-mail: Gerlese.Åkerlind@anu.edu.au

Phone: + 61261250056

Fax: + 61261254023

\begin{abstract}
Discussions of the nature and purpose of postdoctoral contract research positions is an area where assumptions and stereotypes tend to predominate. This is due to (a) recent changes in the higher education sector that have impacted on postdoctoral positions in a way that conflicts with traditional expectations, and (b) a relative lack of data and publications on postdoctoral positions, which creates a climate in which stereotypes can continue relatively unchallenged. This is unfortunate, because it limits the ability of supervisors to provide sound career advice to their postdocs as well as the ability of postdocs to make informed career decisions.
\end{abstract}

Based on an extensive study of PDRs in Australia, this paper challenges four commonly held assumptions:

1. that postdoctoral researchers want an academic career;

2. that postdoctoral research positions provide a stepping stone to academic careers;

3. that postdoctoral research positions provide an opportunity for novice researchers to become increasingly independent; and
4. that postdoctoral research positions provide an opportunity for the incumbents to concentrate solely on research.

\section{Introduction}

Whilst studies of doctoral research training have been growing apace since the 1990s, studies of postdoctoral research training are still relatively rare. Nevertheless, the nature of postdoctoral training and the career prospects of postdoctoral contract researchers (PDRs) has been receiving a growing degree of attention over the past decade (Åkerlind, 2005; Thompson et al, 2001; Nerad and Cerny, 1999; Helbing et al, 1998; Science journal special issue, 1999). This is primarily in response to reduced academic employment opportunities for PDRs, as an outcome of dramatic rises in the numbers of $\mathrm{PhDs}$ and PDRs without a corresponding rise in the number of academic positions.

In the UK and Australia, government policy papers have emphasised the need for broader skills development for those in postdoctoral positions, as career preparation for both academic and non-academic employment (Marceau and Preston, 1996; HM Treasury, 2000; Borthwick and Wissler, 2003). In line with this, research funding bodies in both countries have been supporting opportunities for broader skills development of PDRs. The primary research funding body in Australia, the Australian Research Council (ARC) offers a teaching and research fellowship, on a $75 \%$ ARC funding and $25 \%$ host institution funding basis. In the UK, the research funding councils have agreed on a joint skills training statement for the PDRs (and 
PhDs) they fund (Research Councils UK, 2001). This requires 10 days training per year in personal and professional skills for each student, and provides some $£ 500$ per PDR to fund such training activities. In addition, the European Community has established a European Charter for Researchers and Code of Conduct for the Recruitment of Researchers, with the aim of providing more open and sustainable career prospects for researchers (European Commission, 2005).

These policy emphases acknowledge that there are not enough academic positions available for the number of PDRs seeking them, that many PDRs move into non-academic careers, and that broader skills training is required to address the breadth of career options for PDRs. However, they do not consider the way in which these changes are being experienced by PDRs.

This paper is based on extensive study of postdoctoral training and employment outcomes in Australia. The study consisted of a questionnaire survey of some 1011 PDRs, selected from the range of universities in Australia, accompanied by follow-up interviews with 22 PDRs, plus 10 postdoctoral supervisors. The overall results of this study have been reported elsewhere (Thompson et al, 2001). The purpose of this paper is to use the data to explore four commonly held assumptions about the nature of postdoctoral positions:

1. that postdoctoral researchers want an academic career;

2. that postdoctoral research positions provide a stepping stone to academic careers;

3. that postdoctoral research positions provide an opportunity for novice researchers to become increasingly independent; and

4. that postdoctoral research positions provide an opportunity for the incumbents to concentrate solely on research.

These assumptions derive from traditional views of the nature of postdoctoral positions, but this paper will argue that each of these assumptions needs to reassessed in the current higher education climate.

\section{Methods}

The arguments presented here are based on three sources of data:

1. an online survey of 1011 PDRs from 38 universities in Australia;

2. an in-depth interview with a sample of 22 PDRs, selected from those who completed the survey; and

3. an in-depth interview with 10 supervisors of PDRs, nominated by the PDRs who were interviewed.

\section{Survey of PDRs}

In common with other countries, the first problem with a survey of PDRs was, first, defining, then second, locating the population of PDRs.

A consistent problem besetting research into PDRs is the lack of an agreed definition as to what constitutes a PDR (Åkerlind, 2005; Thompson et al, 2001). There is variation between universities in the titles assigned to PDRs, and in whether these researchers are classified as academic or non-academic staff. Further, many PDRs work outside of universities, conducting research for industry or government. As the focus of this study was on postdoctoral research in universities (also representing those 
researchers most likely to be interested in an academic career), and within Australian universities postdoctoral contract research positions are most commonly classified as academic appointments, the definition used for this study was: a fixed term, research only, base-grade academic appointment, with PhD qualification.

It should be noted that this definition excludes three categories of contract researchers that other studies may include, i.e. fixed-term researchers on academic appointments but without a $\mathrm{PhD}$, fixed-term researchers with a $\mathrm{PhD}$ but not classified as an academic appointment, and contract researchers working outside of a university setting. The Australian context is important here, in that within Australia it is common for postdoctoral research positions to be academic positions, these variations, issues and expectations facing postdoctoral researchers are similar internationally (Thompson et al, 2001; Nerad and Cerny, 1999; Helbing et al, 1998; Science journal special issue, 1999).

Once defined, the problem of identifying the population was addressed. In no case was there a separate institutional record of PDRs; in all cases PDRs had to be identified from a larger base of university personnel, often on the basis of their position name. This means that the number of PDRs identified was probably an underestimate of the population. The primary position names of the selected population were: Postdoctoral Fellow, Postdoctoral Research Fellow, Research Associate, Research Officer, Research Fellow, Senior Research Associate.

\begin{tabular}{|l|l|}
\hline Discipline \\
\hline Engineering/Architecture/Building & $85(8.4 \%)$ \\
Mathematics & $34(3.4 \%)$ \\
Physical sciences & $68(6.7 \%)$ \\
Chemistry & $80(7.9 \%)$ \\
Earth sciences & $57(5.6 \%)$ \\
Biology & $257(25.4 \%)$ \\
Information technology/Computing & $22(2.2 \%)$ \\
Agriculture/Vet/Environment & $68(6.7 \%)$ \\
Medical health & $206(20.4 \%)$ \\
Social sciences & $79(7.8 \%)$ \\
Humanities & $55(5.4 \%)$ \\
Total & 1011 \\
& $(100 \%)$ \\
\hline
\end{tabular}

Table 1: Research field and level of appointment of participating PDRs

with academic employment rights and responsibilities. This is in contrast to the UK, where it is more usual for postdoctoral positions to be nonacademic positions, representing nonacademic employment, and North America, where it is common for postdoc positions to be regarded as non-employment training positions, without employee rights. Despite
In total, 2800 PDRs were identified. PDRs were invited by e-mail to participate in the survey by completing an online questionnaire. Of the original $2800,428 \mathrm{did}$ not have a valid e-mail address, and 63 responded saying that they did not fit the definition. Of the remaining 2309, 1011 (43\%) completed the questionnaire.

Responses by field of study are presented in Table 1 . Not surprisingly, there is a predominance of science disciplines, particularly medical and earth sciences, but also a representation of the humanities and social sciences. 


\begin{tabular}{|l|lll|}
\hline University type & Identified PDRs & Total responses & Response rate* \\
\hline A: Group-of-eight & $2051(73.3 \%)$ & $716(70.8 \%)$ & $42 \%$ \\
B: post-1960 univ & $522(18.6 \%)$ & $190(18.8 \%)$ & $40 \%$ \\
C: ex-Colleges & $62(2.2 \%)$ & $37(3.7 \%)$ & $65 \%$ \\
D: Unitechs & $165(5.9)$ & $68(6.7 \%)$ & $45 \%$ \\
Total & 2800 & 1011 & $43 \%$ \\
\hline
\end{tabular}

Table 2: University type of participating PDRs

*response rate is based on number of valid e-mail addresses, not on number of PDRs identified.

Australian universities are commonly grouped into four institutional types. While all Australian universities engage in both teaching and research, they differ in age, disciplinary foci, research-intensiveness and associated prestige:

A. the oldest and most researchintensive universities (Groupof-Eight);

B. newer but still researchintensive universities (post1960 universities);

C. previous teaching-oriented colleges that were transformed into universities by government policy in the late 1980s (excolleges); and

D. vocationally-oriented universities of technology (unitechs).

Table 2 shows the population and response rate from each university type. The great majority of PDRs are employed in group A or B universities, with $73.3 \%$ in group A alone.

Nevertheless, PDR employment in group $\mathrm{C}$ and $\mathrm{D}$ universities has been increasing in recent times, so it seemed important to capture the experiences of that segment of the population. While there was a higher response rate from group $\mathrm{C}$ than from the other universitytypes, this was counterbalanced by the fact that group $\mathrm{C}$ respondents constituted only $3.7 \%$ of the total sample. Although all of the PDRs were currently employed in an Australian university, 30\% had had their PhD awarded in another country.

\section{Interviews with PDRs}

A sample of 22 PDRs was interviewed, selected from those who completed a survey questionnaire. Each respondent selected had indicated on the questionnaire that they were willing to undertake a follow-up interview. The interviews were semi-structured, consisting of a series of core questions, typically followed by additional questions seeking further information in response to interviewees' answers. In general, the interviews were of approximately 60 minutes duration. The interviews were taped and transcribed verbatim, except in one instance where the interviewee preferred not to be taped. The transcripts were then content analysed, searching for common themes running across the interviews, as well as similarities and differences in response to the issues raised. The resulting themes arose from the data analysis, and were not predetermined.

Interviewees were all selected from group-of-eight universities, as these host the vast majority (approx 75\%) of PDRs in the Australian higher education system. However, within this parameter interviewees were then selected to represent, as far as possible, the variation in the postdoctoral population found in the questionnaire data, with an emphasis on exploring the range of postdoctoral research experience. The PDRs interviewed varied along the dimensions outlined below: 
- Institution -- Located in five Group A universities in four different states of Australia.

- Gender -- Male (12); female (10).

- Age -- 25-29 (3); 30-34 (6); 35-39 (7); 40-44 (1); 45-49 (3); 50-54 (1); 55-60 (1).

- Citizenship -- Australian (15); other (7).

- Research field -- Mathematics (1); physics (2); chemistry (2); earth sciences (2); engineering (3); biological sciences (2); agriculture (3); health sciences (4); social sciences (1); humanities (2).

- University where PhD awarded -- Same university as postdoc position (6); other Australian university (7); overseas university (9).

- Years since award of PhD -- 01 (5); 2-4 (8); 5-10 (4); 11-15 (4); 23 (1).

- Term of current contract -- 12 months (3); 2 years (4); 3 years (8); 4 years (3); 5 years (2); no response (2).

Interview questions focused on what participants do as postdoctoral researchers, what they think a postdoctoral researcher is, their career expectations and their experiences of career support.

\section{Interviews with supervisors}

The sample of supervisors interviewed was similarly selected to enable exploration of variation in the range of views of postdoctoral research, and were asked similar questions to PDRs, but from a supervisory perspective. As there was no preceding survey of supervisors, and thus no collection of broad demographic parameters of supervisors, they were selected by asking those PDRs interviewed to suggest names of supervisors in their area. As a consequence, approximately half of the supervisors who were interviewed were currently supervising one or more of the PDRs interviewed. Of the 18 supervisors invited to participate, five did not respond to the invitation, and four agreed to the interview but were not available at a suitable time. This left a sample of 10 supervisors interviewed, varying along the dimensions outlined below:

- Institution -- Interviewees were selected from the same five universities as the PDRs.

- Gender -- Male (7); female (3).

- Research field -- Physics (1); chemistry (1); earth sciences (1); engineering (2); agriculture (2); health sciences (2); humanities (1).

- Level of appointment Professor (5, including 3 departmental heads); Reader/Associate Professor (3); other (2).

- Experience as a PDR supervisor -- From 1 PDR over 1 year to 30 PDRs over 20 years.

\section{Findings related to the four assumptions}

\section{Assumption 1 - PDRs want an academic career.}

The first question to consider when thinking about postdoctoral positions as preparation for academic careers is whether the holders of such positions actually want an academic career. Here the issue can become confused by the definition of an academic position. For instance, there is variation between countries, and between institutions within countries, as to whether postdoctoral positions are classified as academic - so some PDRs may already be regarded as having an academic career. 
In the survey of PDRs, respondents were asked "Ideally, what type of position would you like next?". Although, 73\% of PDRs said that they wanted an academic position (see Table 3), when their response was limited to academic teaching and research positions only (i.e., with academic research-only positions excluded), the percentage reduced to $41 \%$-- less than half of the sample. In contrast, those wanting a research-only career - either university research $(32 \%)$, or Government or industry research $(16 \%)$ - amounted to $48 \%$ of the sample, with $11 \%$ interested in an 'other' career, such as consultancy, etc.

It is clear that continuing with a research-only career is highly attractive to many PDRs. This result should not be surprising, in the sense that most PDRs will have completed many years of intensely researchoriented activity, starting with their doctoral work and followed by 1-3 positions as a PDR by the time they seek more permanent work. This sort positions as "teaching positions" in contrast to the research positions that they currently held. The shift from a postdoctoral research position to a traditional academic position was seen as representing a shift from research to teaching, with the associated teaching workload seen as impinging heavily on time to do research.
Ideally, I would like to continue researching, but am aware that a full career path for a researcher is not available in the social sciences and humanities in this country. For that reason, a position that combines teaching and researching is the long- term aim (anonymous PDR survey respondent).

\section{Assumption 2 - Postdoctoral research positions provide a stepping stone to academic careers.}

As shown in Figure 1, based on the PDR survey, a substantial number of

\begin{tabular}{|l|ll|}
\hline Ideal position & $\mathbf{N}$ & $\mathbf{\%}$ \\
\hline Academic -- teaching and research & 408 & 41.1 \\
Academic -- research only (incl PDR) & 320 & 32.2 \\
Government research agency or Institute & 76 & 7.7 \\
Industry - research & 78 & 7.9 \\
Industry - non-research & 18 & 1.8 \\
Public service & 2 & 0.2 \\
Self-employed & 14 & 1.4 \\
Other & 13 & 1.3 \\
Undecided & 64 & 6.4 \\
Total & 993 & 100 \\
\hline
\end{tabular}

Table 3: PDRs ideal next position of preparation for academic work inevitably selects for those who enjoy research-based work.

In line with this, during the interviews with PDRs they frequently described academic teaching and research

the PDRs in this sample were still in a contract research position six or more years after the award of their Ph.D., with a mean period of 5.4 years. Similarly, Figure 2 shows many PDRs in their fourth and fifth contract 
position following their Ph.D., with a mean of 2.7 positions.

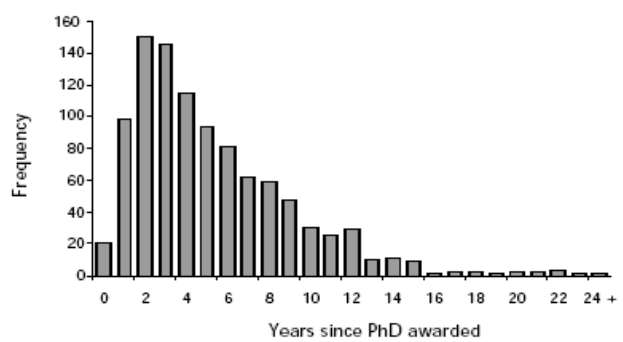

Figure 1: Years since award of $\mathrm{PhD}$

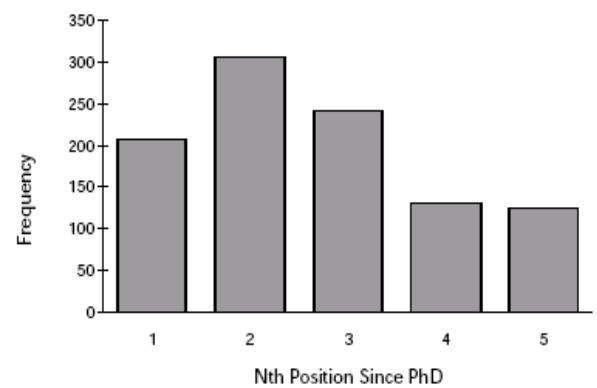

Figure 2: No of contract positions following $\mathrm{PhD}$

Asked to rate their perceptions of their long-term job prospects (in any area of work) on a five-point likert scale (where 1 indicated 'very poor' prospects, 3 'average', and 5 'very good' prospects), only $45 \%$ saw their job prospects as good or very good, and $23 \%$ as poor or very poor (see Figure 3 ), with an overall mean of 3.3 . Interestingly, as shown in the original survey report (Thompson et al, 2001, pp. 55-56), there were no significant differences in the perceived prospects of those from more prestigious, research intensive universities than those from less prestigious universities, or those appointed on more prestigious Fellowship positions than those on less prestigious grant-funded positions.

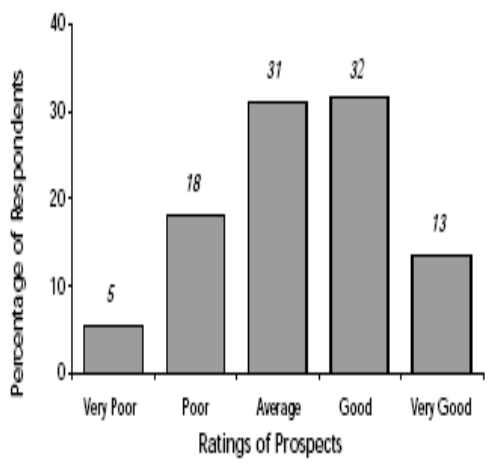

Figure 3: Ratings of long term job prospects

Based on the interviews with PDRs, viewing their position as a stepping stone towards a permanent position was only one perception of the nature of contract research positions. PDRs alternatively described contract positions as (a) being their career, with

ongoing contract research positions the nature of their career, or as (b) an opportunity to engage in research, with career implications of lesser significance. (These different perspectives on the nature of PDR positions are described in more detail in Åkerlind, 2005). Such researchers seem motivated to undertake postdoctoral research by the nature of the research question itself, and the opportunity to investigate this question, irrespective of career implications. For example,

It [a PDR position] means the chance to focus on some of my own research. And it means a job, because I'm not likely to have a career after it... I don't see what comes next. Theoretically, they [PDR positions] are for you to lead into academia or an academic appointment somewhere, but I don't see how at this point (PDR 
interviewee from the social sciences).

\section{Assumption 3 - Postdoctoral research positions provide an opportunity for novice researchers to become increasingly independent}

The majority of PDRs in the survey sample did not see their position as a training position, nor did they see themselves as being supervised (Table 4). postdoc is someone who has finished their doctorate and then worked in that area. So, when do you become not a postdoc? (supervisor interviewee from Agriculture).

Also, PDRs on fellowships are already operating independently, in the sense that they have independently designed their research project and secured the

\begin{tabular}{|lll|lll|}
\hline Training & $\begin{array}{l}\text { Not } \\
\text { Training }\end{array}$ & $\begin{array}{l}\text { No } \\
\text { Resp }\end{array}$ & Independent & Supervised & $\begin{array}{l}\text { No } \\
\text { Resp }\end{array}$ \\
\hline 269 & 698 & 44 & 623 & 276 & 12 \\
$26.6 \%$ & $69.0 \%$ & $4.4 \%$ & $61.6 \%$ & $27.3 \%$ & $11.1 \%$ \\
\hline
\end{tabular}

Table 4: Ratings of PDR positions as training/not training and independent/supervised

Many PDRs did not see their position as a training position because they felt that they were already operating as independent researchers. Perhaps this is not surprising, given the increasing periods of time spent in postdoctoral positions, with most PDRs on their third or later appointment.

I guess in medical research, you do a PhD and then you do a postdoc position, and usually do a series of them... I know people of 55-60 who are still in postdoc research positions (PDR interviewee from medicine).

Again, a postdoc position is a very broad term. ... I always wonder what a postdoc is, and how do you tell that someone is a postdoc?... Because a funding of their salary through applications for research funding.

Independence also varies with disciplinary area. In many areas, science disciplines in particular, a period of postdoctoral research is a virtual requirement in order to achieve academic employment. However, in humanities and social science disciplines, academic appointment immediately post- $\mathrm{PhD}$ is more the norm.

I would emphasise that in my discipline (philosophy), postdocs are not considered training positions. I moved from a being a [higher salaried teaching and research] academic to a [lower salaried research only position] in order to take up this postdoc, partly because the opportunity 


\begin{abstract}
for full time research is very attractive. Given my previous experience, my approach to my postdoctoral work is that of undertaking a large research project, rather than 'training' to do research (anonymous PDR survey respondent).
\end{abstract}

Another reason given by PDRs for not seeing their position as a training position related to a sense of being exploited, with little time allowed for developmental activities within their appointment. For example,

What training? As far as I
am aware postdocs come
straight out of their PhD,
attempt to generate
papers and a career, and
are not trained any
further. In fact, there is
not time for such training
because most of the time
is spent on research in the
lab (anonymous PDR
survey respondent).

Some supervisors also acknowledged the variability in developmental opportunities between different PDR positions. For example,

It depends very much on the supervisor how much freedom the supervisor gives in running a lab and whether the supervisor treats the postdoc as an equal colleague as opposed to just a slave... the majority of postdocs, they are tied to a particular grant and project and that is their job. However, I always tell them that as far as I am concerned... I give them $20 \%$ freedom to do anything that they like. But that is me. It doesn't mean that that is normal practice (supervisor interviewee from Engineering).

\section{Assumption 4-Postdoctoral research positions provide an opportunity to concentrate solely on research}
Well, it [a PDR position]
is a luxurious, beautiful entity, where one is able to, by and large, focus on a specific research project. So that most of your field of view is occupied by the single task of performing research in a specified area (supervisor interviewee from Engineering).

During interviews, the PDR supervisors were asked to describe the role played by PDRs within their department. While supervisors from all disciplines described PDRs as 'enriching the intellectual life of their department', and supervisors from laboratory-based disciplines emphasised the role played by PDRs as day-to-day managers of the research lab and in informally guiding and supervising research students and more junior PDRs, other roles were rarely mentioned.

In contrast, the online survey explicitly investigated duties carried out by PDRs in addition to their research. Respondents were asked about their involvement in four areas: supervision (formally, as a member of the supervisory panel, and informally, in terms of day-to-day training and 
advice), lecturing, tutoring/demonstrating and conference organisation. Respondents were also asked to list any other duties that they undertook, and to indicate the percentage of their time spent on these duties. Table 5 shows that just over $50 \%$ reported being involved in formal supervision of research students, almost $40 \%$ in lecturing, and a quarter in tutoring/demonstrating and conference organisation.

\begin{tabular}{|l|l|}
\hline Additional Duty & \\
\hline $\begin{array}{l}\text { Formal Supervision }(N= \\
\text { 1,001) }\end{array}$ & $52.6 \%$ \\
Informal Supervision $(N$ & $78.7 \%$ \\
$=988)$ & \\
Lecturing $(N=997)$ & $39.0 \%$ \\
Tutoring/Demonstrating & $24.8 \%$ \\
$(N=976)$ & \\
Conference Organisation & $25.5 \%$ \\
$(N=977)$ & \\
\hline
\end{tabular}

Table 5: Additional duties performed by PDRs-fixed choice response

Table 6 shows the large range of other duties also reported, though less frequently than the duties in Table 5.

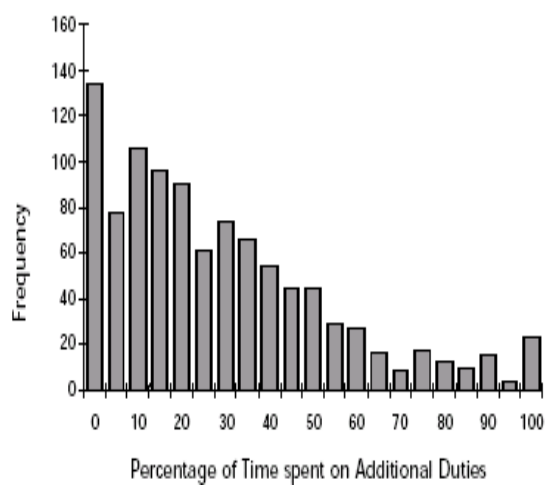

Figure 4: Proportion of time spent on additional duties

As shown in Figure 4, only 127 respondents $(13 \%)$, did not report engaging in additional duties, and for just over $50 \%$ of the sample such additional duties were estimated as taking up more than $20 \%$ of their time. Perhaps even more surprisingly is the existence of some postdocs who report spending the majority of their time on 'additional' duties. In the interviews, some PDRs reported acting as more of a supervisor's aide (i.e. undertaking

any duties requested of them by their supervisor) than a researcher, which may explain this unexpected finding.

\section{Discussion}

It has often been said that the intensive research nature of a PDR position provides poor preparation for the range of activities that typically constitute an academic position, particularly due to the absence of preparation for teaching. However, this argument is normally a skills-based one, that is, that PDR positions are often not providing training in teaching and other academic skills. While this point is valid, an additional point that has emerged from this research is that the intensive research nature of PDR 
positions may not be a good way to select for people who are interested in a broader range of academic activities. Indeed, $48 \%$ of the PDR sample regarded a research-only position (whether or not in academia) as their

\begin{tabular}{|l|l|}
\hline Additional duty & $\begin{array}{l}\text { No. of } \\
\text { respondents } \\
\text { reporting }\end{array}$ \\
\hline University administration & 252 \\
\hline Group or project manager & 129 \\
\hline Grant applications & 87 \\
\hline Committee work & 69 \\
\hline $\begin{array}{l}\text { Staff or group } \\
\text { supervision }\end{array}$ & 56 \\
\hline Reviewer/editor/examiner & 43 \\
\hline External administration & 28 \\
\hline $\begin{array}{l}\text { Conference/seminar } \\
\text { preparation }\end{array}$ & 23 \\
\hline Consultancies & 23 \\
\hline Clinical duties & 4 \\
\hline
\end{tabular}

Table 6: Additional duties performed by PDRs - open choice response

ideal employment, with only $41 \%$ preferring a teaching and research position.

At the same time, a surprising number of PDRs are engaged in significant amounts of non-research duties. Based on the sample described here, over $50 \%$ are involved in formal supervision of research students, almost $40 \%$ in lecturing, and a quarter in tutoring/demonstrating and also conference organisation. Furthermore, for over $50 \%$ of the sample, such nonresearch duties were estimated as taking up more than $20 \%$ of their time. This indicates that PDRs may commonly receive a higher degree of experience in a breadth of academicrelated duties than is usually recognised. Unfortunately, the opportunities for such experience seem to be more commonly available in an ad hoc than systematic way, with substantial variation between different PDR positions. .

Another implication of the large number of PDRs engaged in nonresearch activities is that, while the contribution made by PDRs to research productivity within the higher education sector is well-known, they are making a much more substantial contribution to teaching and supervision across the sector than is typically recognised.

Another issue highlighted here is that some PDRs do not see contract research as an interim stage to a permanent position. Given their commitment to research, some have the intention of continuing to undertake ongoing contract research positions indefinitely, as the only way in which they can maintain a research career, despite the obvious insecurity and other disadvantages. Others choose to take a PDR position in order to focus on research for as long as they can, even though they do not believe that ongoing contract research positions will be available long-term.

Over the last decade in particular, $\mathrm{PhD}$ awards and subsequent PDR positions have risen at a much faster rate than academic positions. The knock-on effect of this, in terms of a reducing proportion of $\mathrm{PhDs}$ and PDRs finding academic employment, is well-known. Under the current situation of intense competition for a limited number of academic positions, one would expect that PDRs in more prestigious universities and appointed on more prestigious research fellowships would have a decided advantage. It is interesting then that there was no significant difference in perceptions of their long-term job prospects amongst the PDRs in these more prestigious positions. Of course, perceptions of 
job prospects and actual job prospects need not coincide, but at the least these findings indicate widespread uncertainty amongst PDRs with respect to their career prospects.

Perhaps the most surprising outcome of this study is the high proportion of PDRs who consider that they are already engaged in independent research and do not see themselves as being in a training position. This may be due to both the large number who are in their third or later postdoctoral position, and thus who have accumulated extensive experience as a researcher, and to the variable nature of the development and training opportunities available across postdoctoral positions. Either way, if contract research positions are not training positions, then it is hard to regard them as anything other than exploitative in nature since they lack permanency.

The key implications of this research for preparation of PDRs for academic careers lies in highlighting the hidden variation in the nature of PDR positions. The research duties undertaken by PDRs, the amount of supervision and training received, opportunities and obligations to engage in non-research duties, motivations of PDRs, and future career aspirations are highly variable in a way that cannot be predicted by the position title, institutional setting, funding type or discipline of PDRs. This makes a one size fits all approach to PDR development unlikely to be effective, and emphasises the need for provisions that are as varied and flexible as possible.

\section{Acknowledgments}

The research reported here was funded by the Evaluations and Investigation Programme (EIP) of the then
Australian Department of Education, Training and Youth Affairs and by the Centre for Educational Development and Academic Methods of the Australian National University. This paper draws on the original EIP report (Thomson et al., 2001), however, the conclusions are those of the present author. A modified version of this paper has previously been presented at the 2007 annual conference of the Society for Research in Higher Education, Brighton UK.

\section{References}

Åkerlind, G.S. (2005) PDRs: Roles, Functions and career prospects, Higher Education Research and Development, 24, pp. 21-40.

Borthwick, J. and Wissler, R. (2003) Postgraduate Research Students and Generic Capabilities: Online Directions, Research Evaluation Programme, Higher Education Group, DEST, Commonwealth of Australia: Canberra.

European Commission (2005) The European Charter for Researchers and The Code of Conduct for the Recruitment of Researchers. EUR21620www.europa.eu.int/eracareers/euro peancharter

HM Treasury (2000) SET for Success, Roberts report

www.hmtreasury.gov.uk/Documents/Enterpris $\mathrm{e}$ and Productivity/Researchand

Enterprise/ent_res_roberts.cfm.

Helbing, C. C., Verhoef, M. J., \& Wellington, C. L. (1998). Finding identity and voice: A national survey of Canadian postdoctoral fellows. Research Evaluation, 7(1), 53-60.

Marceau, J., \& Preston, H. (1996). Taking the lead: The ARC Fellowship Scheme in Australia. Canberra: Australian Government Publishing Service.

Nerad, M., \& Cerny, J. (1999). Postdoctoral patterns, career advancement and problems. Science, 285, 1533-1535.

Research Councils UK (2001) Joint Statement of Skills Training Requirements of Research Postgraduates-http://www.grad.ac.uk/cms/ShowPage/Home 
page/Policy/National_policy/Research_Counci 1s_training_requirements/p!eaLXeFl

Science journal special issue on postdoctoral researchers, 285(3), September 1999.

Thompson J., Pearson, M., Åkerlind, G., Hooper, J., \& Mazur, N. (2001). Postdoctoral training and employment outcomes, EIP Report 01/10. Canberra: Higher Education Division, DETYA. 
